\title{
Rendimento de madeira serrada de espécies de Eucalyptus
}

\author{
Lumber efficiency of Eucalyptus species
}

\section{Rui André Maggi dos Anjos e Ana Paula Namikata Fonte*}

\author{
Recebido em 29/04/2016 / Aceito em 08/09/2016
}

\section{RESUMO}

O rendimento é uma informação relevante, pois indica a porcentagem do volume original da tora que foi efetivamente transformada em madeira serrada e, portanto, reflete a qualidade da operação de conversão de toras. O presente estudo teve por objetivo ampliar os conhecimentos sobre o processamento mecânico da madeira do gênero Eucalyptus. Foi conduzido o desdobro de 72 toras de três espécies: Eucalyptus dunnii, Eucalyptus grandis e Eucalyptus saligna, as quais foram comparadas quanto ao rendimento do processo em função da espécie e em função da separação das toras em três classes de diâmetro. Adicionalmente avaliaram-se algumas características relacionadas à qualidade do fuste e aquelas atribuídas a manifestação das tensões de crescimento para verificar sua influência sobre o rendimento. Os resultados apontaram que as toras de maior diâmetro das espécies E. saligna e E. grandis foram as que forneceram os maiores rendimentos, seguidas das toras de classe de diâmetro intermediário. Já as toras de E. dunnii apresentaram os piores desempenhos para as três classes diamétricas avaliadas, o que pode ser atribuído a forma das toras e também por conta da manifestação de tensões de crescimento durante o processo de desdobro.

PALAVRAS-CHAVE: processamento de toras, classes de diâmetro, tensões de crescimento.

\section{ABSTRACT}

The yield of lumber is one of the main parameters of evaluation of log sawing. Using this information, you can judge the quality of the conversion of logs into sawed parts. This variable indicates the percentage of the original volume of the log that has been transformed into lumber. Therefore, this study aimed to expand knowledge of the mechanical processing of Eucalyptus wood. For this, we employed $72 \operatorname{logs}$ of three species: Eucalyptus dunnii, Eucalyptus grandis and Eucalyptus saligna. We compared the income of lumber of the three species, as well as three diameter classes per species. Additionally we evaluated some characteristics of the shape of the stem and phenomena that occurred during the sawing. The results showed that the larger diameter logs from E. saligna and E.grandis obtained the best performances in income, then the logs of the two intermediate species. The logs from E. dunnii had the worst performance among the three diameter classes, due to the shape of the logs and the manifestation of growth stresses during sawing.

KEYWORDS: wood processing, diameter, tension of growing.

\section{INTRODUÇÃO}

O rendimento da madeira serrada é um dos principais parâmetros de avaliação do desdobro de toras, pois pode auxiliar no planejamento da produção, otimizando os processos, e aumentando a produção. Por meio dessa informação, é possível julgar a eficiência das operações de conversão de toras em peças serradas (ROCHA 2002). Esta variável indica a porcentagem do volume original da tora que foi transformada em madeira serrada.

Sobre os fatores que influenciam o processamento mecânico das toras, PONCE (1995), ROCHA (2000), ROCHA \& TOMASELLI (2002), FERREIRA et al. (2004) e BIASI \& ROCHA (2007) concordam que o rendimento é influenciado por fatores inerentes à madeira, como dimensões e a qualidade da tora e fatores próprios da indústria, como técnica de desdobro empregada, tipo de equipamento, afiação das serras e até o nível técnico e experiência dos operários. 
O rendimento é fundamental para avaliar a capacidade de produção de uma determinada espécie e para estabelecer as estratégias de ação para o processamento. Sem a informação do rendimento, não há como dimensionar a estrutura industrial da serraria. Nesse sentido WIPIESKI et al. (2002) recomendam simulações de modelos de corte para a determinação dos melhores rendimentos, concluindo que essa informação é peça chave para determinar os limites da engenharia do projeto da serraria, bem como a sua futura competitividade e viabilidade financeira.

O objetivo do desdobro é conseguir o máximo de volume de material serrado com o mínimo de desperdício. Mesmo as peças serradas que não se destinam ao objetivo geral da produção devem ser tratadas de forma a se obter boa qualidade, pois ainda podem ser comercializadas a preços menores do que aquelas manufaturadas normalmente (BIASI \& ROCHA 2007). Os mesmos autores, ao estudarem o rendimento de três espécies tropicais, notaram uma tendência de redução do aproveitamento em toras de menores diâmetros, embora não tenham conseguido captar diferenças estatísticas significativas entre as classes diamétricas observadas, e por tal razão recomendaram maior atenção nas operações com essas toras para evitar o desperdício.

A variação do rendimento causada pelo diâmetro da tora é explicada por VIANANETO (1984) da seguinte forma: para obtenção de quantidades desejadas de madeira serrada a partir de toras de diâmetros pequenos, é necessária a movimentação de uma quantidade de peças muito maior, se comparada àquelas oriundas de toras de grandes dimensões. Ainda segundo o mesmo autor, a indústria que trabalha com toras de pequenos diâmetros necessita de um contínuo aperfeiçoamento para que o seu desempenho no aproveitamento da madeira não sofra qualquer prejuízo.

Na pesquisa de SOUZA (2006) o objetivo foi ajustar modelos matemáticos que melhor explicassem o rendimento em madeira serrada, de híbridos de eucalipto e para isso coletaram uma série de variáveis da tora. $\mathrm{O}$ modelo que melhor explicou o aproveitamento em madeira serrada considerou o volume da tora como principal indicativo para o rendimento.

O objetivo dessa pesquisa foi ampliar os conhecimentos sobre o rendimento em madeira serrada de espécies do gênero Eucalyptus. Para atingir este objetivo foi avaliado também o efeito do diâmetro de três espécies frequentemente utilizadas na Região Sul do País, tais como Eucalyptus dunnii, E. grandis e E. saligna.

\section{MATERIAL E MÉTODOS}

\section{Obtenção do material}

As toras das espécies Eucalyptus grandis, E. saligna e E. dunnii, utilizadas na pesquisa tiveram origem de experimentos clonais da Klabin S.A. do Paraná, no município de Telêmaco Borba, a uma latitude $24^{\circ} 19^{\prime} 26^{\prime \prime}$ sul e a uma longitude 50 $36^{\prime} 57^{\prime \prime}$ oeste, e 700 metros de altitude. Segundo o IAPAR (1978), pela classificação de Köeppen, o clima nesta região classifica-se como $\mathrm{Cfa}$, subtropical úmido, mesotérmico com verões quentes e geadas menos frequentes.

Foram retiradas toras de árvores plantadas em espaçamento de 2,5 m x 3,0 m, com 11 anos de idade, tendo sido plantadas numa densidade de 1600 árvores por hectare, e na ocasião da coleta de dados contava-se com aproximadamente 600 indivíduos por hectare. Todas as árvores foram mensuradas em termos de diâmetro e altura. Após a separação das plantas em três classes de diâmetro a altura do peito (DAP), foram selecionadas 24 árvores de cada talhão, sendo separadas em grupos com oito unidades cada. As oito árvores mais finas formaram a classe um, os espécimes com diâmetros intermediários a classe dois e os oito exemplares de maiores diâmetros a classe três.

As classes de DAP foram determinadas com base na distribuição normal. Na classe um, encontravam-se as árvores com DAP, abaixo de dois desvios padrões da média da população, a classe três foi composta pelas árvores com DAP acima de dois desvios padrões da média da população. Já a classe dois foi composta do diâmetro das árvores de DAP próximo ao diâmetro médio da população base, ou seja, as que se encontravam entre menos e mais um desvio padrão da média da população.

\section{Extração de toras e procedimentos de desdobro}

As árvores selecionadas foram cortadas rente ao solo e imediatamente enviadas para a serraria JR Madeiras, localizada também no município de Telêmaco Borba, no Paraná. No desdobro foi utilizada a primeira tora das árvores, com 3,2 m comprimento, que tiveram os volumes medidos pelo método de Smalian antes de serem conduzidas para o processo 
de desdobro.

No desdobro utilizou-se uma serra fita vertical simples, duas serras fitas horizontais, uma serra circular múltipla e uma mesa destopadeira. A sequência de cortes empregada no desdobro das toras é apresentada na Figura 1. Na serra fita principal foram realizados os o corte 1 e 2 , a tora então foi rotacionada em $90^{\circ}$ para execução dos cortes 3 e 4 . Os cortes 5 a 7 foram feitos pela serra fita horizontal e a porção restante foi seccionada em serra circular múltipla, mostrada pelos cortes de número 9, por fim todas as peças serradas passaram pela mesa destopadeira ficando padronizadas com $3 \mathrm{~m}$ de comprimento.

$\mathrm{O}$ rendimento em madeira serrada foi obtido a partir da razão matemática entre o volume de madeira convertido em tábuas $\left(\mathrm{m}^{3}\right)$ e o volume inicial da tora $\left(\mathrm{m}^{3}\right)$, expresso em porcentagem.

Adicionalmente foram mensurados os diâmetros nas duas extremidades das toras essa diferença foi dividida pelo comprimento total da tora, a fim de determinar o valor de redução do diâmetro por centímetro da tora. Também foram anotadas se toras apresentavam qualquer tipo de rachaduras de topo.

\section{Análise estatística}

Foram analisados os efeitos da espécie e da classe diamétrica sobre o rendimento em madeira serrada utilizando-se um delineamento em dois fatores, sendo o fator espécie com três níveis (Eucalyptus dunnii, Eucalyptus saligna e Eucalyptus grandis) e o fator classe de diâmetro com 3 níveis (sendo eles diâmetros de 20 a 26,9 cm, 27 a 34 cm e os diâmetros acima de $34 \mathrm{~cm}$ ), o arranjo também testou a existência de interação entre os dois fatores estudados.

A análise de variâncias e a comparação de médias foram efetuadas pelo teste de diferença mínima significativa de Tukey, para um nível de significância
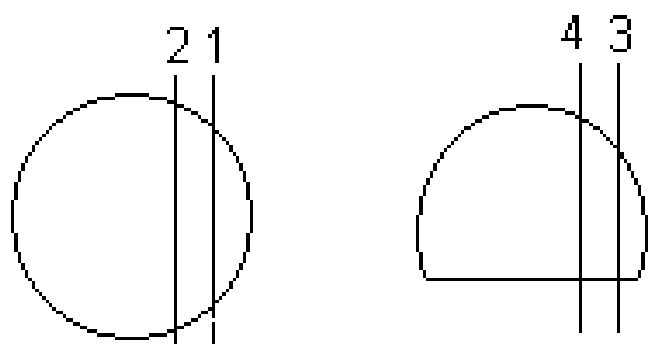

de $95 \%$ de probabilidade.

\section{RESULTADOS E DISCUSSÃO}

O teste de homogeneidade das variâncias comprovou a condição mínima para a aplicação do teste de análise de variância ( $\mathrm{p}$-valor $=0,0001$ ) e teste de normalidade para os valores de rendimento $(\mathrm{p}$-valor $=0,002)$. O resultado da ANOVA rejeitou a hipótese da nulidade para as espécies e para as classes diamétricas (Tabela 1). Ou seja, a espécie influenciou o rendimento, e foram constatadas diferenças entre as espécies e entre os diâmetros. Na Tabela 1, pode-se ver o sumário da análise de variância.

A comparação de médias por Tukey na probabilidade de $5 \%$, com os detalhes dos valores de rendimento encontrados estão na Tabela 2 para o efeito da espécie.

A média de rendimento para a madeira de Eucalyptus grandis foi de $48,55 \%$ para a Classe 1, de $43,85 \%$ para a Classe 2 e $41,07 \%$ para a Classe 3. Para a madeira de E. dunnii os resultados médios de rendimento por classe foram de $49,32 \%$ para a Classe 1, 41,02\% para a Classe 2 e $36,71 \%$ para a Classe 3. E para a madeira de E. saligna, os valores médios de rendimento encontrados foram de $53,55 \%$ para a Classe $1,47,46 \%$ para a Classe 2 e $43,87 \%$ para a Classe 3. Em geral, a madeira de E. saligna foi a que apresentou o maior rendimento, de $48,29 \%$ e a madeira de E.dunnii apresentou o menor rendimento, de $42,35 \%$. Sendo que as três espécies diferiram em relação ao rendimento em madeira serrada.

$\mathrm{Na}$ Tabela 3 apresentam-se resultados combinados entre os efeitos da espécie e do diâmetro em relação ao rendimento, bem como a comparação múltipla efetuada por meio do teste Tukey, a $\alpha=0,05$.

De forma geral, as árvores com maiores diâmetros, independente da espécie, apresentaram

Figura 1 - Esquema empregado para o desdobro das toras. As linhas retas indicam a posição das serras e os respectivos números, a ordem sequencial dos cortes.

Figure 1 - Scheme used for sawing of logs. The straight lines indicate the position of the mountains and their numbers, and the sequential order of the cuts. 
Tabela 1 - Resultados da análise de variância para o rendimento a 95\% de probabilidade.

Table 1 - Income variance analysis results.

\begin{tabular}{cccccc}
\hline Fonte da variação & Soma de quadrados & Graus de liberdade & Quadrado médio & F & P-valor \\
\hline Espécie & 0,006746 & 2 & 0,003373 & 16,3096 & 0,00001 \\
Diâmetro & 0,003182 & 2 & 0,001591 & 7,6943 & 0,001024 \\
Interações Espécie x Diâmetro & 0,001431 & 4 & 0,000358 & 1,7301 & 0,154478 \\
Erro & 0,013029 & 63 & 0,000207 & & \\
Total & 0,024389 & 71 & & & \\
\hline
\end{tabular}

Tabela 2 - Resultados de rendimento entre espécies e entre classes diamétricas e teste de médias para o efeito da espécie.

Table 2 - Yield results for the three species with the three diameter classes and Tukey's test summary to the effect of the species.

\begin{tabular}{lccccccc}
\hline Espécie & $\begin{array}{c}\text { DAP médio } \\
(\mathrm{cm})\end{array}$ & $\begin{array}{c}\text { Rend. } \\
\text { Classe 1 }\end{array}$ & $\begin{array}{c}\text { DAP médio } \\
(\mathrm{cm})\end{array}$ & $\begin{array}{c}\text { Rend. } \\
\text { Classe 2 }\end{array}$ & $\begin{array}{c}\text { DAP médio } \\
(\mathrm{cm})\end{array}$ & $\begin{array}{c}\text { Rend. } \\
\text { Classe 3 }\end{array}$ & $\begin{array}{c}\text { Comparação } \\
\text { Tukey 5\% }\end{array}$ \\
\hline E. grandis & 39,34 & $48,55 \%$ & 35,33 & $43,85 \%$ & 34,9 & $41,07 \%$ & $44,49 \%$ B \\
E. dunnii & 35,33 & $49,32 \%$ & 28,93 & $41,02 \%$ & 23,52 & $36,71 \%$ & $42,35 \%$ B \\
E. saligna & 33,58 & $53,55 \%$ & 24,75 & $47,46 \%$ & 22,24 & $43,87 \%$ & $48,29 \%$ A \\
Média & 36,08 & $50,47 \%$ & 29,67 & $44,11 \%$ & 26,88 & $40,55 \%$ & $45,04 \%$ \\
\hline
\end{tabular}

também os maiores rendimentos em madeira serrada. Estatisticamente, as árvores se apresentaram iguais entre si, incluindo-se nesse grupo a classe diamétrica três do E. saligna, de menores diâmetros.

Esta mesma tendência é relatada por BIASI \& ROCHA (2007), que embora não tenham encontrado diferenças estatísticas significativas entre os diâmetros por eles estudados, todavia, relataram a mesma tendência de aumento no rendimento com o aumento do diâmetro.

Em todas as classes de diâmetro, o Eucalyptus saligna apresentou os maiores valores médios de rendimentos em relação às demais espécies, embora, estatisticamente tenha se apresentado superior às outras espécies.

A interação entre os fatores espécie e diâmetro é significativa apenas a nível de $84,36 \%$, este valor é abaixo dos usuais $95 \%$ de probabilidade de acerto. $\mathrm{O}$ formalismo estatístico indicaria a rejeição da interação, mas este grau de influência mútua entre os fatores não pode ser considerado desprezível. A evidência mais clara de interação entre classe de DAP e espécie é percebida nas performances de rendimento. As toras obtidas das árvores com os maiores DAPs foram as árvores de melhores performances em rendimento. Outro destaque que indica a interação entre os fatores é percebido no resultado da classe DAP dois de $E$. saligna com DAP médio de $24 \mathrm{~cm}$, que apresentou rendimento estatisticamente igual ao do E. grandis com DAP de $35 \mathrm{~cm}$. A interação entre os fatores do ponto de vista estatístico deve ser considerada não significativa para o nível de $5 \%$ de significância, contudo, em níveis de $10 \%$ ocorre a interação entre os resultados, o que pode ser evidenciado pelos resultados.

As diferenças médias entre os diâmetros das extremidades das toras e o número de toras rachadas, são apresentados na Tabela 4.

Ao analisar os dados contidos na Tabela 4, percebe-se que a espécie E. saligna apresentou o menor número de toras rachadas, com as menores diferenças entre os diâmetros da ponta grossa e da ponta fina da tora.

A comparação classe-a-classe mostrou que, de forma geral, o E. saligna, além de apresentar as menores conicidades e em número de toras rachadas, também apresentou os melhores rendimentos em cada uma das classes. Sendo o oposto do verificado $\operatorname{com} E$. 
Tabela 3 - Resumo do teste de Tukey-Kramer para a comparação de médias de rendimento. Table 3 - Summary Tukey-Kramer test for comparing averages yield.

\begin{tabular}{lcc}
\hline \multicolumn{1}{c}{ Diâmetro } & DAP médio $(\mathrm{cm})$ & Rendimento médio \\
\hline E. saligna classe 1 & 33,58 & $53,55 \% \mathrm{~A}$ \\
E. saligna classe 2 & 24,75 & $47,46 \% \mathrm{AB}$ \\
E. grandis classe 1 & 39,34 & $48,55 \% \mathrm{AB}$ \\
E. dunnii classe 1 & 35,33 & $49,32 \% \mathrm{AB}$ \\
E. grandis classe 2 & 35,33 & $43,85 \% \mathrm{AB}$ \\
E. saligna classe 3 & 22,24 & $43,87 \% \mathrm{BC}$ \\
E. dunnii classe 2 & 28,93 & $41,02 \% \mathrm{CD}$ \\
E. grandis classe 3 & 34,9 & $41,07 \% \mathrm{CD}$ \\
E. dunnii classe 3 & 23,52 & $36,71 \% \mathrm{D}$
\end{tabular}

Letras iguais correspondem a médias estatisticamente iguais ao nível de 5\% de probabilidade pelo teste de Tukey-Kramer.

Tabela 4 - Resultados da análise da conicidade da tora e da presença de rachaduras de topo.

Table 4 - Test results of the taper of the log and the presence of top cracks.

\begin{tabular}{ccccccc}
\hline \multirow{2}{*}{ Classe de DAP } & \multicolumn{2}{c}{ E. grandis } & \multicolumn{2}{c}{ E. dunnii } & \multicolumn{2}{c}{ E. saligna } \\
& (D-d/cm) & Toras rach. & (D-d/cm) & Toras rach. & (D-d/cm) & Toras rach. \\
\hline 3 & 3,84 & 3 & 3,34 & 3 & 4,59 & 1 \\
2 & 5,22 & 4 & 4,58 & 2 & 3,78 & 2 \\
1 & 5,69 & 3 & 6,17 & 3 & 4,36 & 1 \\
Média & 4,92 & & 4,7 & & 4,27 &
\end{tabular}

Legenda: (D-d/cm) valor médio para cada classe da diferença entre diâmetro da ponta grossa para o diâmetro da ponta fina dividido pelo comprimento da tora; Toras rach. É a quantidade de toras rachadas por classe diamétrica.

grandis, que apresentou as maiores diferenças entre as extremidades das toras e o maior número de toras rachadas.

Esse fato também se evidencia pela diferença entre os diâmetros maior e menor das toras avaliadas, devido ao formato das toras e as rachaduras produzirem interferência no resultado do rendimento. Esses fenômenos já foram observados e estão em concordância com as observações feitas por SCANAVACA \& GARCIA (2003), que afirmaram ter a forma das toras de E. urophylla, interferência no rendimento da madeira serrada.

$\mathrm{O}$ E. dunnii apresentou o segundo maior número de toras com rachaduras. Adicionalmente, em duas toras da classe um dessa espécie, no momento do desdobro, a porção presa ao carro porta-tora partiu-se por ocasião do segundo corte, fazendo com que a peça restante precisasse de duas passagens na resserradeira, o que interferiu negativamente no aproveitamento dessas toras.

O trabalho de GARCIA (1995) apresenta uma possível explicação para o resultado do aproveitamento, observado nas toras de E. dunnii, pois ao serrar as toras de eucalipto em cortes tangenciais, a peça serrada sofre empenamento enquanto a porção fixa ao carro porta-tora tem seus esforços de compressão e flexão desequilibrados a cada novo seccionamento. Portanto, ficando as forças de flexão e compressão superiores as que unem os tecidos, ocorre à ruptura.

Apoiado nos relatos de GARCIA (1995), SCANAVACA \& GARCIA (2003) e observando os resultados de campo deste trabalho, averiguou-se que, em E. dunnii as manifestações das tensões de crescimento reduziram o aproveitamento da madeira, visto que foi a única espécie que apresentou toras e 
peças rachadas durante o processamento.

Porém existem muitas notificações de toras com a presença de rachaduras, indicando que esse fator interfere negativamente no rendimento. Isso pode ser visto em SCANAVACA \& GARCIA (2003), FERREIRA et al. (2004) e BIASI \& ROCHA (2007).

A comparação múltipla de médias revelou que as toras provenientes de árvores com DAPs próximos a $35 \mathrm{~cm}$ apresentaram maiores aproveitamentos em madeira serrada. Esses valores encontram-se em acordo com os valores obtidos por SOUZA (2006). Os resultados também indicam, que sempre no desdobro de toras grossas de E. grandis e E. saligna foram obtidos os maiores rendimentos, se comparados a $E$. dunnii.

Em relação à comparação entre o rendimento das espécies estudadas, o E. dunnii apresentou a pior performance, com rendimento médio de $42 \%$ para a maior classe de diâmetro, que são valores superiores aos calculados por ROCHA (2000). Por outro lado, para esse mesmo estudo, a espécie E. grandis apresentou rendimento médio de $44,41 \%$, e a espécie E. saligna apresentou rendimento médio de $48,31 \%$. Comparando-se os resultados de JUÍZZO et al. (2014), o rendimento do presente estudo para a madeira de $E$. saligna nas 3 classes diamétricas, pode-se afirmar que os resultados deste experimento foram superiores.

No que tange o rendimento médio, os híbridos clonais de Eucalyptus sp. de FERREIRA et al. (2004) apresentaram um rendimento entre 30,1 a 51,5\%, valores inferiores aos encontrados nesse estudo.

Os trabalhos de ROCHA \& TOMASELLI (2001) e ROCHA \& TOMASELLI (2002) corroboraram com os resultados do presente trabalho e observaram que o diâmetro pode influenciar a qualidade das peças serradas.

ACOSTA (1999) relatou valores de rendimento de $41 \%$, para E. grandis, mas mencionou também que os rendimentos vão de $41 \%$ a $48 \%$, atribuindo a diferença na performance às classes diamétricas e ao sistema de desdobro. Tais valores foram compatíveis aos valores obtidos para madeira de E. grandis do presente estudo.

ROCHA (2000) obteve valores compatíveis com o presente estudo, sendo que para as toras de menor diâmetro de E. grandis (19 a $24 \mathrm{~cm})$ foi encontrado o rendimento médio de $48,22 \%$ e para as toras de maior diâmetro de E. dunnii $(25$ a $30 \mathrm{~cm})$ foi encontrado um rendimento médio de $36,77 \%$. No entanto, para as toras de menor diâmetro de E. dunnii,
ROCHA (2000) encontrou valores inferiores a este estudo, com rendimento de $41,68 \%$ e para as toras de maior diâmetro de E. grandis os valores foram superiores ao estudo, com rendimento igual a $43,19 \%$.

De forma geral, o rendimento de madeira serrada mostrou-se diretamente proporcional ao diâmetro médio das toras entre as espécies estudadas e as árvores com DAPs próximos a $35 \mathrm{~cm}$ foram as que apresentaram os maiores aproveitamentos em madeira serrada. Os resultados menos expressivos foram obtidos em toras com diâmetros médios próximos a $20 \mathrm{~cm}$.

Análises subjetivas para auxiliarna interpretação dos resultados estatísticos sobre as espécies florestais e o número de rachaduras desenvolvidas no decorrer da prática de desdobro, demonstraram que o E. saligna foi a espécie que apresentou as menores diferenças entre os diâmetros da ponta grossa e da ponta fina da tora e o menor número de toras rachadas. Como consequência, também apresentou os melhores rendimentos entre espécies, em cada uma das classes.

\section{CONCLUSÃO}

O maior rendimento em madeira serrada foi obtido pela espécie E.saligna, seguida das espécies $E$. grandis e E. dunnii.

As toras com diâmetros acima de $35 \mathrm{~cm}$ de diâmetro apresentaram as melhores performances. Os diâmetros abaixo de $20 \mathrm{~cm}$ apresentaram os piores rendimentos em madeira serrada.

\section{REFERÊNCIAS}

ACOSTAMS. 1999. Experiencia Argentina en la producción y utilización de la madera de eucalipto, panorama a 1999. In: Workshop: técnicas de abate, processamento e utilização da madeira de eucalipto. Viçosa, UFV.

BIASI CP \& ROCHA MP. 2007. Rendimento em madeira serrada e quantificação de resíduos para três espécies tropicais. Floresta 37: 95-108.

FERREIRA $\mathrm{S}$ et al. 2004. Influência de Métodos de Desdobro Tangenciais no Rendimento e na Qualidade da Madeira de Clones de Eucalyptus spp. Cerne 10: 10-21.

GARCIA JN. 1995. Técnicas de Desdobro de Eucalipto. In: 59 Seminário Internacional de Utilização da Madeira de Eucalipto para Serraria. Anais... São Paulo. p.67.

IAPAR - Instituto Agronômico do Paraná. 1978. Cartas climáticas básicas do estado do Paraná. Instituto Agronômico do Paraná, Londrina.

JUÍZO CGF et al. 2014. Avaliação do rendimento em madeira serrada de eucalipto para dois modelos de desdobro 
numa serraria portátil. Floresta e Ambiente 21: 543-550.

PONCE RH. 1995. Madeira Serrada de Eucalipto: desafios e perspectivas. In: 59 Seminário Internacional de Utilização da Madeira de Eucalipto para Serraria. Anais... São Paulo. p.50-58.

ROCHA MP. 2002. Desdobro da Madeira, FUPEF, Série didática, Curitiba, 126p.

ROCHA MP \& TOMASELLI I. 2001. Efeito de Modelo de Corte nas Dimensões De Madeira Serrada de Eucalyptus grandis e Eucalyptus dunnii. Floresta e Ambiente 8: 94103.

ROCHA MP \& TOMASELLI I. 2002. Efeito do Modelo de Desdobro na Qualidade da Madeira Serrada de Eucalyptus grandis e Eucalyptus dunnii. Cerne 8: 70-83.

ROCHA MP. 2000. Eucalyptus grandis Hill ex Maiden e Eucalyptus dunnii Maiden como Fontes de Matéria Prima para Serrarias. Dissertação (Doutorado em Ciências Florestais). Curitiba: UFPR. 185p.

SCANAVACA JR L \& GARCIA JN. 2003. Rendimento em madeira serrada de Eucalyptus urophylla. Scientia Forestalis 63: 32-43.

SOUZA MAM. 2006. Metodologias não destrutivas para avaliação das tensões de crescimento em Eucalyptus dunnii Maiden. Dissertação (Doutorado em Ciências Florestais). Curitiba: UFPR. 130p.

VIANA NETO JAA. 1984. Considerações básicas sobre o desdobro de Pinus sp.. Anais do Seminário sobre processamento e utilização de madeiras de reflorestamento 9: 15-23.

WIPIESKI CJ et al. 2002. SISCORTE: uma ferramenta de otimização de serrarias. Curitiba: STCP. p.22-25. (Informativo $\mathrm{n}^{\circ} 6$ ). 